\title{
Influence of individual or group housing of newborn calves on rotavirus and coronavirus infection during the first 2 months of life
}

\author{
E. A. Bertoni ${ }^{1} \cdot$ M. Bok ${ }^{2} \cdot$ C. Vega ${ }^{2} \cdot$ G. M. Martinez ${ }^{3} \cdot$ R. Cimino ${ }^{4} \cdot$ V. Parreño ${ }^{2}$ \\ Received: 27 July 2020 / Accepted: 1 December 2020 / Published online: 3 January 2021 \\ (C) The Author(s), under exclusive licence to Springer Nature B.V. part of Springer Nature 2021
}

\begin{abstract}
Bovine rotavirus $\mathrm{A}(\mathrm{RVA})$ and bovine coronavirus $(\mathrm{CoV})$ are the two main viral enteropathogens associated with neonatal calf diarrhea. The aim of the present work was to study the impact of group and individual housing systems in the epidemiology of RVA and CoV infection. Eleven calves reared in individual housing (FA) and nine calves in group housing (FB) were monitored during the first 7 weeks of life. Stool and serum samples were screened for RVA and $\mathrm{CoV}$ antigens by ELISA. IgG1 antibodies (Ab) to both antigens were also measured. From the 160 fecal samples collected, the proportion of positive samples to RVA and CoV was significantly higher in FB (23.6\%) than in FA (9\%) $(p=0.03)$. The geometric mean of colostral IgG1 Ab titers to CoV and RVA in FA (IgG1 anti-CoV 1024 and anti-RVA 1782.9) was lower than in FB (IgG1 anti-CoV 10,321.2 and anti-RVA 4096) at birth. Calves less than 2 weeks of life from FB had a higher risk of being infected by RVA $(\mathrm{OR}=4.9 ; p=0.01)$ and $\mathrm{CoV}(\mathrm{OR}=17.15 ; p=0.01)$ than calves from FA. The obtained results showed that there was higher RVA and CoV shedding in group-housed calves than in individual-housed animals.
\end{abstract}

Keywords Bovine coronavirus · Bovine rotavirus · Dairy calf · Group housing · Individual housing · Longitudinal study

\section{Introduction}

Bovine rotavirus $\mathrm{A}(\mathrm{RVA})$ and bovine coronavirus $(\mathrm{CoV})$ are the two main viral enteropathogens associated with neonatal calf diarrhea (Afshari Safavi et al. 2012), and they are widely distributed throughout the world (Ghosh et al. 2008). They are

\section{E. A. Bertoni}

bertoni.emiliano@inta.gob.ar

$\triangle$ V. Parreño

parreno.viviana@inta.gob.ar

1 Área de Investigación en Salud Animal, Instituto de Investigación Animal del Chaco Semiárido, INTA, RN 68 km 172., Postal code 4403 Salta, Cerrillos, Argentina

2 INCUINTA. Instituto de Virologia e Tecnológicas, IVIT. CICV y A. Instituto Nacional de Tecnología Agropecuaria (INTA). Unidad ejecutora INTA-CONICET, Nicolas Repetto y de los Reseros s/n., Postal code 1686 Buenos Aires, Argentina

3 Área de Producción Animal, INTA EEA, Salta, Argentina

4 Cátedra de Química Biológica, Facultad de Ciencias Naturales, UNSA, Salta, Argentina well-recognized etiologic agents of the neonatal calf diarrhea syndrome together with other pathogens. Risk factors related to the surrounding environment and management practices can have a direct effect on the incidence and the epidemiology of those viral diarrheas. One of these factors is the housing system for rearing calves (Marcé et al. 2010). Cross-sectional surveys reported that systems using individual housing minimize enteric pathogen infections (Barrington et al. 2002) and decrease the risk of diarrhea (Gulliksen et al. 2009; Curtis et al. 2016).

Concerning to RVA and CoV infections in calves, there are just a few longitudinal studies, and most of them were performed in dairy farms with individual housing systems (McNulty and Logan 1983; Heckert et al. 1990; Coura et al. 2014; Bok et al. 2017). Thus, the true impact of the housing systems with regard to transmission and infection rates of bovine RVA and CoV in calves was not fully explored.

The objective of this study was to determine the impact of the calves' individual or group housing systems in the epidemiology of RVA and CoV in calves from dairy farms through a longitudinal study. 


\section{Materials and methods}

\section{Geographic area and characteristics of farms studied}

Lerma Valley is located in Salta province from Argentina, between 1100 and $1450 \mathrm{~m}$ above sea level, which absolute maximum temperatures stand out in November, reaching up to $40.9{ }^{\circ} \mathrm{C}$, while July records absolute minimums of $-8.1{ }^{\circ} \mathrm{C}$ (Belmonte 2009; Martinez 2015). There are a total of 51 dairy farms with approximately 6500 Holstein cows in milking each (Suarez and Martinez 2015). The number of lactating cows in farm A (FA) and in farm B (FB) was 180 and 370 and an average of 23 and 25 of milk/cow/day, respectively. Both farms used a vaccine to prevent diarrheas with two doses 60 and 30 days prior to delivery as a general protocol.

\section{Study design and data collection}

The longitudinal study was performed on two dairy farms in 2015 between May and July. In FA, 11 calves were studied from birth until 7 weeks of life. The calves stayed with the dam 48-72 $\mathrm{h}$ after calving and then were housed tied in individual stakes until 2 months of life. They were fed with 41 of raw milk (non-pasteurized, at a temperature of $37^{\circ} \mathrm{C}$ ) per day and calf starter ad libitum (Santa Silvina). In FB, 9 calves were studied from birth until 7 weeks of life. Calves were separated from their mothers after calving, and they were fed with 41 of frozen-thaw colostrum before the first $12 \mathrm{~h}$ of life. They were housed in groups of 10 animals until 2 months of life, with a straw bed and a roof covering $50 \%$ of the pen, and they were fed with milk replacer (4 1 per calf per day, at a temperature of $37^{\circ} \mathrm{C}$ ) and calf starter ad libitum (Santa Silvina).

To evaluate neonatal diarrhea in calves, samples were scored as non-liquid and liquid feces. This last one was defined as feces without consistency and complete dispersion in the floor or the container.

\section{Fecal and serum samples and diagnosis procedures}

Fecal and blood samples were taken once a week during the first 7 weeks of life. The first collection was on the day of birth after administration of colostrum. Aliquots of fecal samples were diluted $10 \%(\mathrm{w} / \mathrm{v})$ in phosphate saline buffer $(\mathrm{pH} 7)$ and conserved at $-20^{\circ} \mathrm{C}$ and $-70{ }^{\circ} \mathrm{C}$ until the analysis of bovine RVA and CoV, respectively. Polyclonal indirect enzymelinked immune sorbent assay (iELISA) was performed for RVA antigen detection (Garaicoechea et al. 2006; Badaracco et al. 2013) and a monoclonal iELISA for CoV antigen detection (Smith et al. 1996). Serum samples were conserved at $20{ }^{\circ} \mathrm{C}$ until the analysis. The IgG1 antibody (Ab) titers to RVA and CoV were measured using a double sandwich ELISA (Fernandez et al. 1996; Parreño et al. 2004; Bok et al. 2017).

\section{Data analysis}

Every sample was considered as an individual event. Descriptive analysis was conducted with the central tendency, and dispersion statistics and pathogen-specific and diarrhea prevalence were calculated. Odds ratio (OR) and confidence interval (CI 95\%) were calculated to estimate if there was a relationship between RVA and $\mathrm{CoV}$ shedding and the housing system. Fisher's exact test and Pearson Chi-squared $\left(\chi^{2}\right)$ test were used to establishing the degree of association. Geometric mean IgG1 antibody (Ab) titers (GMTs) to RVA and CoV determined by ELISA were $\log 10$-transformed before the statistical analysis. The IgG1 Ab titers to RVA and $\mathrm{CoV}$ were analyzed by a general linear mixed statistical model (GLMM) using the glm function (Epicalc packages 2.15.1.0) where the best-fit model was the one with the smallest Akaike information criterion (AIC), and the analysis was performed with RStudio 1.2.1335 (Bok et al. 2017). Statistical differences between the area under the curve (AUC) of diarrhea were calculated with the receiver operator characteristic (ROC) curve with the software Prism 5 version 5.01. Statistical significance was assessed at $p<0.05$ for all comparisons.

\section{Results}

The proportion of calves infected at least once with RVA and $\mathrm{CoV}$ was $63.3 \%(7 / 11)$ and $100 \%(9 / 9)$ in FA and FB, respectively. In total, 160 fecal samples from 20 calves were collected. The proportion of samples positive to RVA and $\mathrm{CoV}$ is higher in FB (23.6\%) than in FA (9\%) for both antigens, being this difference statistically significant (Fisher exact test, $p=0.03$ ) (Table 1). Only one calf from FA is co-infected with both viruses (calf \#11, on day 35, Tables 2 and 3 ).

The distribution of RVA and $\mathrm{CoV}$ infections during the first 7 weeks of life in calves from FA (individual housing) and FB (group housing) is presented in Fig. 1 a and b. In calves from FA, RVA shedding was registered between 21 and 42 days of life, while $\mathrm{CoV}$ shedding was detected only in two calves on day 2 and day 35, respectively. In calves from $\mathrm{FB}$, both RVA and $\mathrm{CoV}$ antigens were mostly detected in the first 2 weeks of life. The individual housing was a protector

Table 1 Fecal samples positive to RVA and $\mathrm{CoV}$

\begin{tabular}{llll}
\hline \multirow{2}{*}{ Farm } & \multicolumn{2}{l}{$\%$ of positive fecal samples } \\
\cline { 2 - 4 } & CoV & RVA & Total \\
\hline A & $2.2 \%(2 / 88)$ & $9 \%(8 / 88)$ & $9 \%(8 / 88)$ \\
B & $5.5 \%(4 / 72)$ & $18 \%(13 / 72)$ & $23.6 \%(17 / 72)$ \\
Fisher exact test $p$ value & 0.4 & 0.1 & 0.03 \\
\hline
\end{tabular}


Table 2 RVA IgG1 Ab titers measured at birth (0 days) and then every 7 days

\begin{tabular}{|c|c|c|c|c|c|c|c|c|c|c|}
\hline Farm & Calf & 0 days & 7 days & 14 days & 21 days & 28 days & 35 days & 42 days & 49 days & $\mathrm{SC}$ \\
\hline \multirow[t]{12}{*}{ A } & 1 & 256 & 1024 & 1024 & 256 & 256 & 256 & 256 & 1024 & No \\
\hline & 2 & 1024 & 1024 & 1024 & 1024 & 1024 & 4096/RVA & 256 & 1024 & No \\
\hline & 3 & 1024 & 1024 & 1024 & 1024 & 1024 & 1024/RVA & 1024 & 256 & No \\
\hline & 4 & 4096 & 4096 & 4096 & 1024/RVA & 4096 & 4096/RVA & 1024 & 4096 & No \\
\hline & 5 & 4096 & 64 & 64 & 64 & 64 & 64 & 1024 & 1024 & Yes \\
\hline & 6 & 256 & 256 & 256 & 1024 & 256 & 256/RVA & 1024/RVA & 1024 & No \\
\hline & 7 & 4096 & 4096 & 1024 & 1024 & 256 & 1024 & 1024 & 1024 & No \\
\hline & 8 & 4096 & 4096 & 4096 & 4096 & 1024 & 1024 & 1024 & 1024 & No \\
\hline & 9 & 4096 & 4096 & 4096 & 1024 & 1024 & 256 & 256 & 1024 & No \\
\hline & 10 & 1024 & 1024 & 1024 & 4096 & 4096/RVA & 1024 & 1024 & 4096 & No \\
\hline & 11 & 4096 & 4096 & 4096 & 4096 & 1024 & 1024/RVA & 1024 & 1024 & No \\
\hline & GM & 1782.9 & 1317.5 & 1494.5 & 1024 & 701.6 & 701.6 & 701.6 & 1161.5 & \\
\hline \multirow[t]{10}{*}{ B } & 12 & 4096 & 1024/RVA & 256/RVA & 256 & 1024 & 1024 & 1024 & 256 & Yes \\
\hline & 13 & 1024 & 1024/RVA & 256/RVA & 256 & 256 & 256 & 4026 & 256 & Yes \\
\hline & 14 & 16,384 & 4096 & 4096 & 4024 & 1024 & 1024 & 1024 & 1024 & No \\
\hline & 15 & 4096 & 1024/RVA & 1024 & 4024 & 1024 & 1024 & 1024 & 1024/RVA & No \\
\hline & 16 & 1024 & 16,384 & 256/RVA & 256 & 4096 & 4096 & 16,384 & 4096/RVA & Yes \\
\hline & 17 & 16,384 & 1024 & 1024 & 4024 & 256/RVA & 256 & 256 & 256 & No \\
\hline & 18 & 4096 & 4096 & 4096 & 1024 & 256/RVA & 256 & 1024 & 16,384 & Yes \\
\hline & 19 & 4096 & $16,384 /$ RVA & 4096/RVA & 256 & 4096 & 1024 & 256 & 1024 & Yes \\
\hline & 20 & 4096 & 4096 & 4096/RVA & 4096 & 4096 & 1024 & 1024 & 1024 & No \\
\hline & GM & 4096 & 3444.3 & 1896.1 & 1385.2 & 1024 & 752.5 & 1021.8 & 1024 & \\
\hline
\end{tabular}

$R V A$ ELISA virus shedding. $S C$ seroconversion. $G M$ geometrics mean

factor for infection with RVA in calves less than 2 weeks of life $(\mathrm{OR}=0.09$; IC 95\% $=0.005-1.647 ; p=0.04)$ in FA, while calves less than 2 weeks of life from FB showed higher risk of becoming infected by RVA $(\mathrm{OR}=4.9$; IC 95\% = $1.362-17.84 ; p=0.01)$ and $\mathrm{CoV}(\mathrm{OR}=17.15$; IC $95 \%=$ $0.888-331 ; p=0.01)$ than older animals in that farm.

The proportion of samples with diarrhea was not significantly different between farms (FA 18/88; FB 11/72; Fisher exact test, $p=0.4)$. In FA 63\% (7/11) and FB 77\% (7/9) of calves had at least one episode of diarrhea, with 2.5 and 1.3 diarrhea cases per day, respectively. The distribution of diarrhea during the first 7 weeks in FA and FB animals is presented in Fig. 2. In FA, at 7 days of life, the prevalence of calves with diarrhea reached the maximum, and in general terms, it remained constant until the end of the study. In FB, since the first days of life (day 0), we found sick calves with a maximum prevalence at 7 and 21 days of life, where it starts declining until the end of the study. The AUC of diarrhea was not significantly different among groups (ROC curve, $p=0.2$ ). There was not a significant association between virus shedding and diarrhea.

Results of anti-RVA and anti-CoV IgG1 Ab titers in calf sera from FA and FB are presented in Tables 2 and 3 and Fig. 1c and d. Geometric mean of colostral IgG1 Ab titers to $\mathrm{CoV}$ and RVA at 0 days in FA was 1024 and 1782.9, respectively, while in FB was 10, 321.2 and 4096 for $\mathrm{CoV}$ and RVA, respectively. The IgG1 Ab titers to $\mathrm{CoV}$ were statistically different between both farms (GLMM, $p=0.004$, AIC 46.1), while no significant differences were observed in the IgG1 Ab titers to RVA at this time point ( 0 days of life). The area under the curve (AUC) of the IgG1 Ab titers anti-CoV and anti-RVA in both farms showed a significant difference only in the profile of IgG1 to CoV (ROC curve, $p=0.03$ ).

Finally, $27.7 \%$ (3/11) of calves (\#1, \#8, and \#10) from FA showed anti-CoV IgG1 seroconversion even when CoV shedding was not detected with the methodology used in the samples taken weekly. Regarding anti-RVA IgG1 Ab response, only $9 \%(1 / 11)$ of calves (\#5) show seroconversion without RVA detection in feces (Tables 2 and 3). On the other hand, 44.4\% (4/9) of calves (\#14, \#17, \#18, and \#19) from FB showed anti-CoV IgG1 seroconversion, and three of them shed $\mathrm{CoV}$ in feces detectable by ELISA. Anti-RVA IgG1 seroconversion is observed in $55.5 \%$ (5/9) of the calves (\#12, \#13, \#16, \#18, and \#19) from FB, where four of them shed RVA detectable by the ELISA assay used in this study (Tables 2 and 3). 
Table $3 \mathrm{CoV}$ IgG1 Ab titers measured at birth ( 0 days) and then every 7 days

\begin{tabular}{|c|c|c|c|c|c|c|c|c|c|c|}
\hline Farm & Calf & 0 days & 7 days & 14 days & 21 days & 28 days & 35 days & 42 days & 49 days & $\mathrm{SC}$ \\
\hline \multirow[t]{12}{*}{ A } & 1 & 1024 & 4096 & 4096 & 1024 & 256 & 256 & 4096 & 4096 & Yes \\
\hline & 2 & 1024 & 4046 & 4096 & 1024 & 256 & 256 & 256 & 256 & No \\
\hline & 3 & 4096 & 16,384 & 4096 & 4096 & 4096 & 4096 & 1024 & 4096 & No \\
\hline & 4 & 4096 & 4096 & 4096 & 4096 & 4096 & 1024 & 1024 & 1024 & No \\
\hline & 5 & $4096 / \mathrm{CoV}$ & 256 & 256 & 16 & 4 & 4 & 4 & 4 & No \\
\hline & 6 & 1024 & 256 & 256 & 256 & 256 & 256 & 256 & 256 & No \\
\hline & 7 & 4096 & 16,384 & 4096 & 4096 & 4096 & 4096 & 4096 & 1024 & No \\
\hline & 8 & 1024 & 1024 & 1024 & 65,536 & 1024 & 1024 & 4096 & 256 & Yes \\
\hline & 9 & 1024 & 4096 & 1024 & 1024 & 1024 & 1024 & 1024 & 1024 & No \\
\hline & 10 & 4 & 4096 & 4096 & 4096 & 1024 & 1024 & 4096 & 1024 & Yes \\
\hline & 11 & 1024 & 4096 & 4096 & 4096 & 4026 & $1024 / \mathrm{CoV}$ & 4096 & 1024 & No \\
\hline & GM & 1024 & 2803.3 & 1695.2 & 1695.2 & 700.5 & 545.3 & 902.7 & 545.3 & \\
\hline \multirow[t]{10}{*}{ B } & 12 & $16,384 / \mathrm{CoV}$ & 4096 & 1024 & 1024 & 1024 & 1024 & 1024 & 256 & No \\
\hline & 13 & 16,384 & 4096 & 1024 & 1024 & 256 & 1024 & 1024 & 1024 & No \\
\hline & 14 & $16,384 / \mathrm{CoV}$ & 4096 & 4096 & 16,384 & 1024 & 16,384 & 4096 & 1024 & Yes \\
\hline & 15 & 4096 & 4096 & 1024 & 1024 & 1024 & 4096 & 4096 & 4096 & No \\
\hline & 16 & 16,384 & 16,384 & 16,384 & 16,384 & 4096 & 65,536 & 4096 & 4096 & No \\
\hline & 17 & 4096 & 4096 & $4096 / \mathrm{CoV}$ & 1024 & 1024 & 4 & 1024 & 1024 & Yes \\
\hline & 18 & 65,536 & 4096 & 1024 & 1024 & 4096 & 16,384 & 1024 & 1024 & Yes \\
\hline & 19 & $4096 / \mathrm{CoV}$ & 4096 & 4096 & 16,384 & 16 & 1024 & 1024 & 1024 & Yes \\
\hline & 20 & 4096 & 4096 & 4096 & 4096 & 4096 & 4096 & 4096 & 4096 & No \\
\hline & GM & $10,321.2$ & 4778.1 & 4778.1 & 3010 & 877.2 & 2211.9 & 2048 & 1717.7 & \\
\hline
\end{tabular}

CoV ELISA virus shedding. $S C$ seroconversion. $G M$ geometrics mean

\section{Discussion}

The aim of the present study was to determine if housing conditions and other management practices including colostrum intake (directly from their dams or artificial feeding) of calves less than 7 weeks of life are risk factors for $\mathrm{CoV}$ and RVA infections and disease through a longitudinal study. In this survey, we observed in the group-housed system (FB) a higher RVA and $\mathrm{CoV}$ infection rates in calves. These results agree with general recommendations where calves should be reared in individual pens until 3 weeks of age, where avoiding direct contact between animals would help to minimize transmission of viral infections (Radostits 1991; Gulliksen et al. 2009; Curtis et al. 2016).
Fig. 1 a RVA and CoV shedding in FA (individual housing). b RVA and CoV shedding in FB (group housing). $\mathbf{c}$ IgG1 antiRVA Ab titers in FA and FB. d IgG1 anti-CoV Ab titers in FA and FB
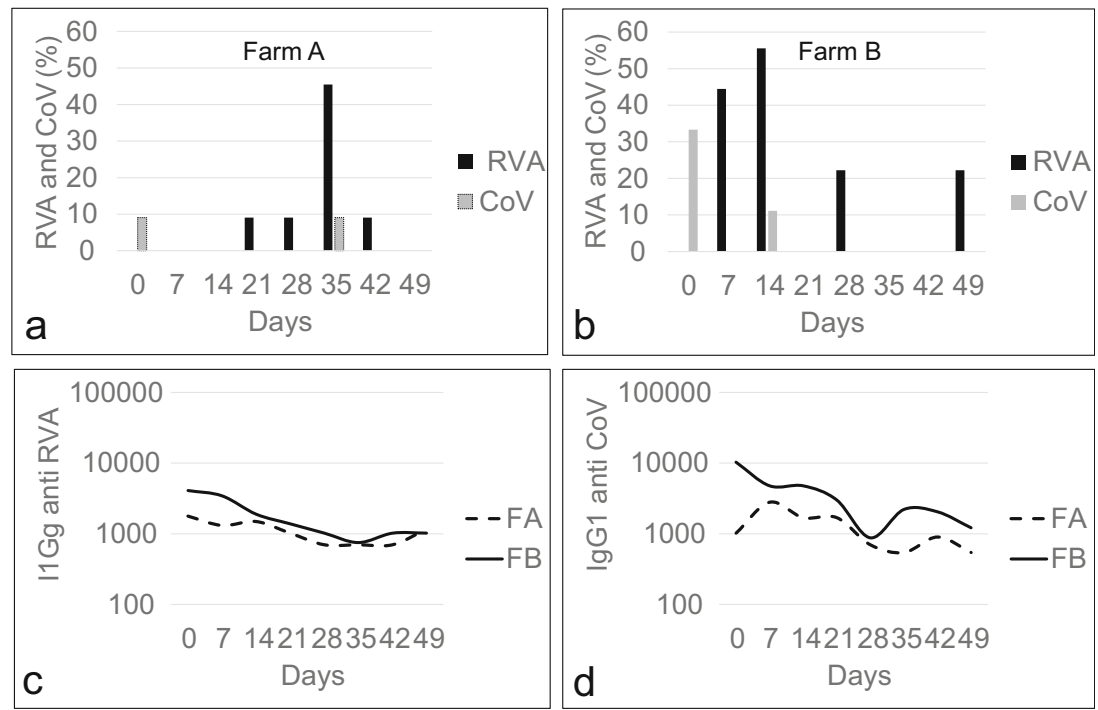


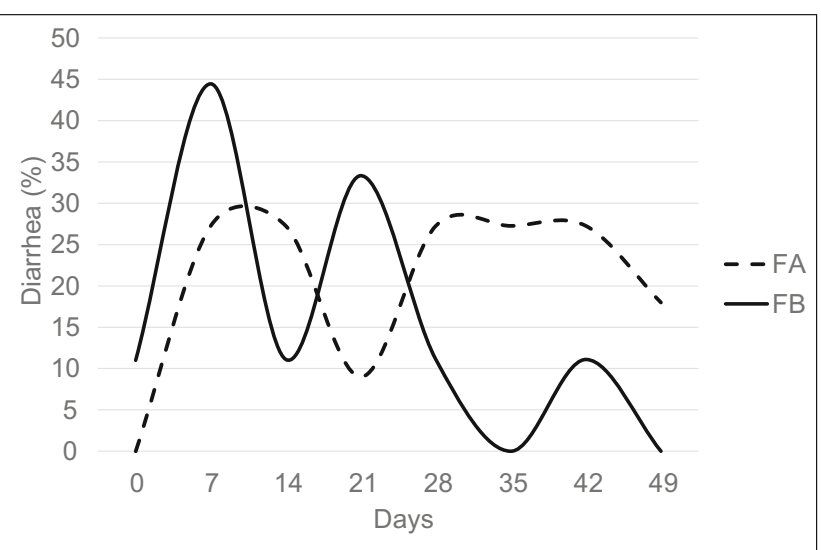

Fig. 2 Neonatal calf diarrhea and virus shedding in FA and FB

Regarding the time frame of virus shedding throughout this study, RVA and CoV were observed among 3 to 6 weeks of life in the individual-housed animals and in the first 2 weeks of life in the group-housed animals. These results are in agreement with Heckert et al. study in which calves housed in hutches or tied showed fecal and respiratory $\mathrm{CoV}$ shedding starting at 4 weeks of life (Heckert et al. 1990). However, our results differ from other longitudinal surveys in which RVA and $\mathrm{CoV}$ shedding was detected in the first 3 weeks of life in calves housed individually (McNulty and Logan 1983; Coura et al. 2014; Bok et al. 2017), while other surveys reported that RVA shedding starts at 30 days of life in most of the calves living in groups (Nagata et al. 1987). Strikingly, there was not a significant association between virus shedding and diarrhea. Probably, the reduced number of calves enrolled in the study and taking one sample per week was not enough to find this association.

Regarding the immune response of calves in different rearing systems, in group-housed calves (FB), where colostrum was artificially administered with bottles, the Ab titers (GM IgG1 Ab titer anti-CoV at day $0=10,321.2$ and GM IgG1 Ab titer anti-RVA at day $0=4096$ ) were higher than $\mathrm{Ab}$ titers in individual-housed calves (GM IgG1 Ab titer anti-CoV at day $0=1024$ and GM IgG1 Ab titer anti-RVA at day $0=1782.9$ ), where colostrum intake was directly from the dam, similarly as has been reported before (Besser et al. 1991). Despite the higher titer of Abs after colostrum intake in group-housed calves compared with individual-housed calves, a higher proportion of seroconversion and virus shedding in group-housed calves (FB) was observed, confirming the hypothesis that group housing will increase the environmental contaminations with viral pathogens, where calves with high $\mathrm{Ab}$ titers still get infected. However, the fact that calf can get infected without developing diarrhea in the presence of high titers of circulating maternal Ab was previously studied (Parreño et al. 2004). The higher titers of $\mathrm{Ab}$ to $\mathrm{CoV}$ in dam's colostrum and calves' serum in FB could be associated with a higher circulation of this virus in that farm.
It is important to highlight that previous surveys reported optimum titers of passive IgG1 anti-RVA and anti-CoV above 16, 384 and 1024, respectively (Parreño et al. 2004; Bok et al. 2017). Considering that, in this study, $10 \%$ (2/20) and $95 \%$ $(19 / 20)$ of calves had a successful passive transference of IgG1 anti-RVA and anti-CoV, respectively. These results help to explain the greater proportion of calves shedding RVA compared to calves shedding $\mathrm{CoV}$ in feces.

Respect the IgG1 curve in animal 5 for both viruses is really interesting since it was diagnosed with $\mathrm{CoV}$ infection at birth and the animal did not seroconvert for coronavirus during the time-frame of the study but do seroconverted for rotavirus at 42 days. This situation was also reported in a previous survey (Bok et al. 2017). As we can see, this happens in both RVA and CoV titers eliminating a possible error in the moment of the procedures, and this could be explained by a rapid metabolism of the passive antibodies in this particular calf and a longer immune gap than in the other calves. On the other hand, in calves 17 and 19, clearly we see how they get infected with RVA when the titers of passive maternal antibodies decreased. It is hard to explain why calf $17 \mathrm{did}$ not seroconvert for IgG1. The study of IgM and IgA Ab responses in serum and feces might help to understand its behavior. Concerning the late seroconversion for $\mathrm{CoV}$ infection also shows a delay in the $\mathrm{Ab}$ response, although the lack of enough sensitivity of the ELISA for antigen detection can not be discharged. Probably it would have been better to use a more sensitivity technique like RT-PCR.

Since this was an observational study, there was no control of any of the variables that could influence the result. The trends regarding virus infection and diarrhea found throughout the study would probably be more evident (statistically significant) when comparing both rearing systems if a larger number of calves were enrolled and followed daily instead of weekly. Despite the objective was pointed to the study of RVA and CoV, it would have been useful to investigate the other pathogens involved in the microbiology of the neonatal calf diarrhea. These points will be considered in the experimental design of the future field trials.

In this study, we observe how the housing system could influence RVA and $\mathrm{CoV}$ infections in neonatal calves, highlighting the importance of the global approach over the study of neonatal calf diarrhea.

Acknowledgments We are very grateful to Dr. Linda Saif for having kindly provided $\mathrm{CoV}$ monoclonal antibodies for ELISA assays.

Funding This study was funded by the Instituto Nacional de Tecnología Agropecuaria (INTA), Argentina.

\section{Compliance with ethical standards}

Animal rights This article does not contain any experimental studies with animals performed by any of the authors. 


\section{References}

Afshari Safavi, E.A., Mohammadi, G.R., Rad, M., Naghibi, A., 2012. A Case-Control Study of Association between Diarrhea in Newborn Calves and Infection with Rotavirus and Coronavirus in Some Industrial Dairy Herds of Mashhad Aarea , Iran in 2008. Arch. Razi Inst. 67, 35-41. https://doi.org/10.22092/ARI.2016.103885

Badaracco, A., Garaicoechea, L., Matthijnssens, J., Louge Uriarte, E., Odeón, A., Bilbao, G., Fernandez, F., Parra, G.I., Parreño, V., 2013. Phylogenetic analyses of typical bovine rotavirus genotypes G6, G10, P[5] and P[11] circulating in Argentinean beef and dairy herds. Infect. Genet. Evol. 18, 18-30. https://doi.org/10.1016/j. meegid.2013.04.023

Barrington, G.M., Gay, J.M., Evermann, J.F., 2002. Biosecurity for neonatal gastrointestinal diseases. Vet. Clin. North Am. - Food Anim. Pract. 18, 7-34. https://doi.org/10.1016/S0749-0720(02)00005-1

Belmonte, S., 2009. "Evaluación multicriterio para el uso alternativo de energías renovables en la ordenación territorial del Valle de Lerma Salta." National University of Salta.

Besser, T.E., Gay, C.C., Pritchctt, L., 1991. Comparison of three methods of feeding colostrum to dairy calves. J. Am. Vet. Med. Assoc. 198, 419-422.

Bok, M., Alassia, M., Frank, F., Vega, C.G., Wigdorovitz, A., Parreño, V., 2017. Passive immunity to control Bovine coronavirus diarrhea in a dairy herd in Argentina. Rev. Argent. Microbiol. https://doi.org/ 10.1016/j.ram.2017.03.007

Coura, F.M., Freitas, M.D., Ribeiro, J., de Leme, R.A., de Souza, C., Alfieri, A.A., Facury Filho, E.J., de Carvalho, A.Ú., Silva, M.X., Lage, A.P., Heinemann, M.B., 2014. Longitudinal study of Salmonella spp., diarrheagenic Escherichia coli, Rotavirus, and Coronavirus isolated from healthy and diarrheic calves in a Brazilian dairy herd. Trop. Anim. Health Prod. 47, 3-11. https:// doi.org/10.1007/s11250-014-0675-5

Curtis, G.C., Argo, C.M., Jones, D., Grove-White, D.H., 2016. Impact of feeding and housing systems on disease incidence in dairy calves. Vet. Rec. 179, 512. https://doi.org/10.1136/vr.103895

Fernandez, F.M., Conner, M.E., Parwani, A. V., Todhunter, D., Smith, K.L., Crawford, S.E., Estes, M.K., Saif, L.J., 1996. Isotype-specific antibody responses to rotavirus and virus proteins in cows inoculated with subunit vaccines composed of recombinant SA11 rotavirus core-like particles (CLP) or virus-like particles (VLP). Vaccine 14, 1303-1312. https://doi.org/10.1016/S0264-410X(96)00065-5

Garaicoechea, L., Bok, K., Jones, L.R., Combessies, G., Odeón, A, Fernandez, F., Parreño, V., 2006. Molecular characterization of bovine rotavirus circulating in beef and dairy herds in Argentina during a 10-year period (1994-2003). Vet. Microbiol. 118, 1-11. https:// doi.org/10.1016/j.vetmic.2006.06.004

Ghosh, S., Samajdar, S., Sinha, M., Kobayashi, N., Taniguchi, K., Naik, T.N., 2008. Molecular characterization of rare bovine group a rotavirus $\mathrm{G} 15 \mathrm{P}[11]$ and $\mathrm{G} 15 \mathrm{P}[21]$ strains from eastern India: Identification of simian SA11-like VP6 genes in G15P[21] strains. Virus Genes 37, 241-249. https://doi.org/10.1007/s11262-0080260-y

Gulliksen, S.M., Jor, E., Lie, K.I., Hamnes, I.S., Løken, T., Akerstedt, J., Osterås, O., 2009. Enteropathogens and risk factors for diarrhea in Norwegian dairy calves. J. Dairy Sci. 92, 5057-5066. https://doi. org $/ 10.3168 /$ jds.2009-2080

Heckert, R.A., Saif, LJ., Hoblet, K.H., Agnes, A.G., 1990. A Longitudinal Study of Bovine Coronavirus Enteric and Respiratory Infections in Dairy Calves in Two Herds in Ohio. Vet. Microbiol. 22, 187-201.

Marcé, C., Guatteo, R., Bareille, N., Fourichon, C., 2010. Dairy calf housing systems across Europe and risk for calf infectious diseases. Animal 4, 1588-1596. https://doi.org/10.1017/ S1751731110000650

Martinez, G.M., 2015. Caracterización del Valle de Lerma, in: Suarez, V.H., Martinez, G.M. (Eds.), Características y Problemáticas Productivas - Sanitarias de La Lechería Del Valle de Lerma (Salta). Buenos Aires, p. 66

McNulty, M.S., Logan, E.F., 1983. Longitudinal survey of rotavirus infection in calves. Vet. Rec. 113, 333-335. https://doi.org/10.1136/ vr.113.15.333

Nagata, K., Minamiyama, M., Tetsuo, S., Mayata, T., 1987. A Survey on Bovine Rotavirus Type 1-Associated Neonatal Calf Diarrhea in a Beef Herd. Jpn. J. Vet. Sci 49, 23-30.

Parreño, V., Béjar, C., Vagnozzi, A., Barrandeguy, M., Costantini, V., Craig, M.I., Yuan, L., Hodgins, D., Saif, L., Fernández, F., 2004. Modulation by colostrum-acquired maternal antibodies of systemic and mucosal antibody responses to rotavirus in calves experimentally challenged with bovine rotavirus. Vet. Immunol. Immunopathol. 100, 7-24. https://doi.org/10.1016/j.vetimm.2004. 02.007

Radostits, O.M., 1991. The control of infectious diseases of the respiratory and digestive tracts of cattle. Can Vet J 32, 85-89.

Smith, D.R., Tsunemitsu, H., Heckert, R. a., Saif, L.J., 1996. Evaluation of Two Antigen-Capture ELISAs using Polyclonal or Monoclonal Antibodies for the Detection of Bovine Coronavirus. J. Vet. Diagnostic Investig. 8, 99-105. https://doi.org/10.1177/ 104063879600800116

Suarez, V.H., Martinez, G.M., 2015. Características generales de los tambos, in: Suarez, Victor Humberto, Martinez, Gabriela Marcela (Eds.), Características y Problemáticas Productivas - Sanitarias de La Lechería Del Valle de Lerma (Salta). Buenos Aires, p. 66.

Publisher's note Springer Nature remains neutral with regard to jurisdictional claims in published maps and institutional affiliations. 